\title{
Copeptin Measurement
}

National Cancer Institute

\section{Source}

National Cancer Institute. Copeptin Measurement. NCI Thesaurus. Code C127612.

The determination of the amount of copeptin present in a sample. 